\title{
Career success of immigrant professionals: stock and flow of their career capital
}

\author{
Tony Fang and Jelena Zikic \\ Atkinson Faculty of Liberal and Professional Studies, \\ School of Administrative Studies, York University, Toronto, Canada, and \\ Milorad M. Novicevic \\ Management Department, School of Business Administration, \\ University of Mississippi, University, Mississippi, USA
}

\begin{abstract}
Purpose - The purpose of this paper is to investigate how the interplay between individual and organizational human capital investments may impact on immigrant career success

Design/methodology/approach - Analysis is based on the 2003 Canadian Workplace and Employee Survey (WES) in order to determine the impact of training (both self-funded and employer-sponsored) and other human resource practices (such as training expenditure per employee, membership of a team, and job rotation) on employee career outcomes. The most basic estimate is a linear function based on immigrant and non-immigrant sub-samples of the WES.

Findings - A positive relationship was found between employers' investment in training and development (as indicated by their training expenditure per employee), and objective career success indicators (wage and promotions) for non-immigrants but not for immigrant professionals (IPs).

Practical implications - The topic is timely, given the growing need to explore the relationship between the existing labour shortages emerging under the forces of globalization and the talent flow of internationally mobile and experienced professionals. In particular, as organizations strive to become more global, their ability to integrate and leverage the international expertise, language knowledge, and networks that IPs bring with them is paramount.

Originality/value - The study is original and makes a unique contribution because it combines the individualistic and organizational perspectives concerning the stock and flow of human capital with regard to immigrant professionals. While most research to date has focused on the individualistic approach and on capital investments made by the immigrant, the study addresses the equally important organizational perspective.
\end{abstract}

Keywords Immigrants, Careers, Human resource management

Paper type Research paper

\section{Introduction}

As immigrant workforces expand internationally, issues related to managing and better integrating immigrant professionals (IPs) (i.e. those who hold at least a bachelor's degree or equivalent from their home country) are increasingly occupying major policy and research agendas (Chiswick et al., 2005; Kogan, 2006; Alboim and McIsaac, 2007). Because IPs often bring a wealth of knowledge to the local labour market, they can have a major impact on local economies. This impact can be significant not only in countries such as Canada and Australia, which have traditionally attracted many immigrants, but also in many European countries that are experiencing an influx of IPs (Kogan, 2006). As these highly skilled individuals migrate 
across both national and organizational borders, they face major life and career changes and challenges and, most importantly, they alter and internationalize the labour pool.

Most of the past research on immigrant impact has focused on examining macro level structural phenomena that are relevant to labour economists, policy makers, sociologists and geographers (Reitz, 2007a, 2007b). However, these studies have rarely considered the associated social phenomena or what some call the "human face" of migration and immigration (Favell et al., 2006). Among these phenomena are issues influencing the individual career success and career mobility of IPs. The topic of immigrant careers still remains relatively under-researched by management scholars, especially human resource and career researchers. While there is a vast literature on the career dynamics of individuals developing their careers in their country of origin, surprisingly little is known about career progression and obstacles that face immigrant workers when they attempt to continue or re-establish their careers in the host country of immigration (Bhagat and London, 1999). To fill this void, this study investigates how the interplay between individual and organizational human capital investment may impact on immigrant career success. This topic is timely given the growing need to explore the relationship between the existing labour shortages emerging under the forces of globalization and the talent flow of internationally mobile and experienced professionals. In particular, as organizations strive to become more global, their ability to integrate and leverage the international expertise, language knowledge, and networks that IPs bring with them is paramount.

We focus first on barriers to and enablers of immigrant career success. Secondly, we use the theoretical framework of human capital theory to explain the stock and flow components of immigrant human capital. Thirdly, we present our empirical study that tests the influence of immigrant human capital on immigrant career success. In conclusion, we discuss our findings, outline specific implications, and indicate future research directions.

\section{Barriers to immigrant careers}

In spite of the need for a more intense talent flow across national borders, immigrants often experience a variety of barriers in their attempts to re-establish their careers outside the boundaries of their native countries (Carr et al., 2005; Salaff et al., 2002). In particular, immigrants are faced with barriers to transferring their human capital (the economic value of their skill set, accumulated experience, and capacity to learn) to the new labour market of their destination country (Chiswick, 1978; Cobb-Clark et al., 2005). Moreover, it is known that they frequently incur what is called a "transition penalty": a longer period of adjustment to establishment in a new country (Lochhead, 2003). The related stress experienced during this transition and subsequent adaptation process may have important implications for the career success of immigrants in the host country (Bhagat and London, 1999). Therefore, immigrants may be less likely to experience continued career success because they face longer periods of unemployment than do native-born workers. Even when employed, immigrants are often underemployed, working at jobs below their skill levels, and earning wages that are lower than those of the native-born workers (Fang and Heywood, 2006). This situation is especially difficult for immigrant professionals, whose credentials may not be recognized and whose past foreign human capital may be discounted in the new 
country of residence. Finally, these barriers to immigrant integration also impose significant costs upon the local economy (Reitz, 2001).

To deal with the impediments that immigrants encounter upon arrival in the new country of residence, IPs often tend to focus on acquiring additional human capital. Through various career self-management strategies, they try to compensate for losses incurred upon encountering the barriers and improve their chances of obtaining a job that is comparable to the one they had in their home country. These human capital and career investments include learning about the labor market and mastering the language, with the objective of obtaining additional credentials, licences, and training that will allow them to become re-employed quickly and at a suitable level (Peixoto, 2001).

After spending some time in the host country, IPs tend to gradually acquire country-specific knowledge so that they can translate the skills accumulated in their countries of origin into forms rewarded in the host labour market. Thus the earnings gap between immigrant professionals and native-born professionals will narrow over time (Iredale, 2001). Ultimately, the goal for IPs is to re-establish their careers in the host country and achieve desired career success in the new labour market.

In this study we investigate personal and organizational investments in the stock and flow of IPs' human capital and the impact of these investments on IPs' objective and subjective career success. While most previous research has focused on IPs' own investments in acquiring human capital while in their host country, we extend this perspective by examining the role of employers' investments in increasing their IPs' human capital and ultimately their objective and subjective career success. In addition, as a reference for comparison, we include in our analysis a comparable sample of non-immigrant professionals. To interpret this comparison, we need to define the subjective and objective facets of the IPs' career success. This definition is provided in the following section of this paper.

\section{Career success of immigrant professionals}

An established definition of a career is the unfolding sequence of a person's work experiences over time (Arthur et al., 1989). This definition avoids any constraining assumptions about where people work or what represents career success. Careers can also be described in two fundamentally different ways. Subjective careers reflect the individual's own sense of his or her career and what it is becoming (Stebbins, 1970). Objective careers reflect the more or less publicly observable positions, situations, and status "that serve as landmarks for gauging a person's movement through the social milieu" (Barley, 1989, p. 49).

Just as career has an internal as well as an external dimension (Gunz, 1989), so does career success, which also has subjective internal and objective external facets (Judge and Bretz, 1994). Subjective career success refers to "a feeling of pride and personal accomplishment that comes from knowing that one has done one's personal best" (Mirvis and Hall, 1996, p. 26). In contrast, objective career success reflects an external perspective that delineates more or less tangible indicators of an individual's career situation. The objective career is publicly accessible, and includes observable career achievements which can be measured such as pay and promotion rates (Arthur et al., 2005). Both subjective and objective indicators of immigrant career success are the focus of this paper. Although objective career success has long been considered the 
primary way of conceptualizing immigrant career success across a wide range of societies, we argue that the subjective career success of immigrants may also have relevant policy implications for companies and governmental agencies.

\section{Human capital theory: stock and flow of immigrant human capital}

According to human capital theory, individuals make rational choices as to whether or not they want to invest more time, effort, and money in their education and the acquisition of training experience. In other words, they weigh the advantages and disadvantages of these options for investments, including the costs and benefits of such investments (Becker, 1964). This theory posits that the labour market rewards those investments that individuals make in themselves, and that these investments often lead to higher promotion rates and salaries (Becker, 1964). Applied to IPs, this theory would predict that their human capital would increase with the acquisition of job experience and skills that they may obtain by working in the host country.

The concept of human capital has two components, the static stock component and the dynamic flow component. The stock of human capital refers to the list of items that includes levels of education, knowledge, skills, and abilities at a certain point in time. Young, less experienced participants in the labour market commonly focus on items at the top of that list. Although with age, this focus progresses downward, more experienced and educated participants strive to maintain higher levels of all items during their working careers. In contrast to the stock component, the flow component of human capital includes those conscious investments in human capital that, in the form of training and education, enhance individual capacity for ordinary learning (Favell et al., 2006).

Among the items of human capital, level of education, which is the item reflecting the stock that immigrants bring from their countries of origin, has been the subject of most past research. In general, the findings of research studies in labour economics and careers indicate that returns from educational attainment in terms of pay and promotion are significant (Judge et al., 1995). However, studies on immigrant investment in human capital indicate that education and labour market experience acquired abroad are less valued than is experience obtained domestically. It seems that this difference can be explained by indicators of objective career success such as salary, indicating that immigrants are commonly disadvantaged relative to comparable natives (Friedberg, 2000).

Immigrants may improve their chances of following their desired career path by increasing the flow component of their human capital. One way to do that is by engaging in career self-management behaviors such as pursing additional training and development and gaining various types of experience (Zikic and Klehe, 2006). In this way, they are expanding their career capital and at the same time increasing their stock of human capital (Alboim et al., 2005). Career self-management is integral for today's careers, whereby individuals are seen as independent career actors and are less and less able to rely on their organizations' career management efforts (Zikic et al., 2006). This particular perspective may be even more important for immigrants whose transition to a new country makes them mostly self-reliant and requires them to use proactive career behaviors (Kossek et al., 1998; Seibert et al., 1999). 
In this paper we capture these career-related facets of human capital investments by measuring both self-initiated and funded investments and employer-sponsored investments. We also recognize the multidimensionality of the human capital construct by controlling for the levels of education and labor market experiences. This study examines whether IPs invest in their human capital independently of what is offered by their employers through training and development. Specifically, we hypothesize that IPs' independent human capital investments (that are self-initiated and self-funded such as attending additional courses) will be positively related to their subjective and objective career success.

\section{Employers' role in increasing human capital of IPs}

In common with IPs, employers can also influence the stock and flow of their human capital (the aggregate human capital of their employees) by offering them opportunities to accumulate experience during tenure. This can occur through supportive human resource policies that govern training, development, team work, and job rotation. In such ways employers may influence the transition of IPs into the labour market of their new country of residence, their acquisition of local human capital, and ultimately their career success. While past research has mainly looked at individual-level investment in human capital in the host country (e.g., see Chiswick et al., 2005; Cobb-Clark et al., 2005), this study aims to enrich this perspective by examining the impact of employer characteristics on IPs' objective career success.

It appears that IPs' career success can be influenced by both their human agency and the employing organizations' policies that provide a favorable context for their talent flow and integration. Hence, organizations (and societies) should develop policies and practices that encourage and facilitate a developmental process of workplace diversity through proper recruitment and selection, socialization, and other practices that encourage the integration of IPs (Carr et al., 2005). Specifically, some organizational characteristics and the related human resource policies (e.g., training and development initiatives, diversity management) are important because they may directly and indirectly affect employees' career success (Chapman et al., 2005).

The importance of organizational characteristics and policies is supported by studies using person - organization fit theory, which have found that practices such as diversity management are a significant factor in an applicant's job choices over time (Chapman et al., 2005; Ng and Burke, 2005). This effect may, however, be short-lived, as a recent study of newcomers to Canada finds that while new immigrants may perceive organizations with diversity practices as more likely to provide an environment where they can fulfill their career aspirations, perceptions may later become mixed as they become frustrated and demoralized if their career aspirations do not become reality ( $\mathrm{Ng}$ and Burke, 2005). Particular challenges are related to discrepant expectations for practices ranging from personal communication styles to work assignments to performance evaluations. In summary, the goal of this study is to better understand how organizational investments, designed to augment the IPs' human capital, may impact on their career success. We predict that for IPs, organizational investments in human capital (e.g., training and development, team work, and job rotation) will be positively related to their career success. 


\section{Method}

Our analysis is based on the 2003 Canadian Workplace and Employee Survey (WES). The WES is a linked file consisting of both employer and employee components, covering a broad range of topics from both the demand and supply side of the labour market. While employers are sampled by physical location, employees are sampled within each location from employer-provided lists. The survey excluded specific business locations in the Yukon, Nunavut, and the Northwest Territories, along with specific domains such as agriculture; fishing; road, bridge and highway maintenance; government services; and religious organizations (Statistics Canada, 2007). The survey design of the WES is such that it focuses on for-profit organization and certain regions were not selected due to the small population of workplaces and confidentiality concerns.

The WES is a virtually ideal data set for our analysis because it contains a rich array of career success outcome measures. In particular, it contains a direct measure of an individual's total work experience in addition to a measure of job tenure with the current workplace[1]. The WES also contains detailed information on incidences and amounts of workplace training. These high-quality measures of work experience and training are particularly important in light of our stated hypotheses.

This study examines both objective (promotion rate, wage rate) and subjective indicators (job satisfaction, pay satisfaction) of career success as dependent variables. Independent variables examined here concern two types of human capital investment:

(1) engagement in career self-management activities (self-initiated and funded); and

(2) employer investments in human capital, as indicated by training and development expenditures, ability to engage in flexibility toward job rotations, and the use of teams.

Further, we control for various demographic factors (age, gender, marital status, presence of children), human capital factors (level of education, labour market experience), as well as occupation and workplace characteristics (region, industry, foreign ownership, not-for-profit), among others.

Responses were received from 6,565 business locations and 20,834 employees in the 2003 survey. Our sample of interest consists of paid workers (both native-born and immigrant workers) who, in 2003, were between the ages of 18 and 64 and possessed at least an undergraduate, graduate, or professional degree. We also excluded those who immigrated in or after 2002 because the period of immigration is too short to capture their labour market outcomes. This resulted in a sample of 4,105 workers, of which 3,101 were born in Canada and 1,004 immigrated to Canada.

Various methods can be used to examine the associations between the determinants and outcomes by immigration status, including the standard log wage function for wage outcome, an Ordinary Least Squares Regression (OLS) model for the determinants of employee job promotion rate (number of promotions/job tenure), employee job satisfaction, and their satisfaction with compensation.

All models control for various personal characteristics (such as age, gender, marital status, dependent children); human capital characteristics (such as time at immigration, foreign language at home); job characteristics (such as union/collective agreement coverage, years of labour market experience, job tenure, part-time status, incentive pay, and occupation); workplace characteristics (such as region, industry, 
workplace size, foreign ownership, not-for-profit organization); and various workplace practices (such as percentage of part-time workers).

To determine the impact of training (both self-funded and employer-sponsored) and other human resource practices (such as training expenditure, membership on a team, and job rotation) on employee career outcomes, our most basic estimate is a linear function based on the immigrant and non-immigrant sub-samples of the WES:

$$
C_{i j}=\alpha+\beta X_{i j}+\gamma Y_{j}+\varepsilon
$$

where $C_{i j}$ is the career outcome variable of the $i$ th worker in the $j$ th workplace; $\alpha$ is a constant; $X_{i j}$ is a vector of human capital variables for the $i$ th worker in the $j$ th workplace; $Y_{j}$ is a set of characteristics of the $j$ th workplace; and $\varepsilon$ is a randomly distributed error term. The coefficients $\beta$ and $\gamma$ gives us an estimate of the returns of specific individual, job, and workplace characteristics to the outcome measures, controlling for other observed employee and workplace characteristics.

We use the employee survey weights provided by the WES in all of our estimations. In addition, we identify the primary survey units as the establishments at which multiple workers may be interviewed[2]. The resulting estimation of (1) is designed to return representative results and to provide heteroskedasticity-robust standard errors. These errors correct for the common components associated with a cluster of workers from a given workplace. (For more on when to use heteroskedasticity-robust standard errors, see Stock and Watson, 2003, pp. 596-7).

\section{Results}

Descriptive statistics for the main dependent and independent variables are presented in Table I for the sample as a whole and by immigrant status. As shown in previous research, on average, IPs earn less than non-immigrant professionals $(\$ 27.3 / \mathrm{hr} \mathrm{v}$. $\$ 30.1 / \mathrm{hr})$. They also tend to have lower promotion rates $(0.213 \mathrm{v} .0 .258)$ and shorter tenure with their current employer (7.0 years v. 8.3 years). In addition, they are less satisfied with their jobs (3.16 v. 3.29$)$ and compensation ( $2.88 \mathrm{v}$. 3.01$)$ compared with their non-immigrant counterparts.

In terms of self-initiated and self-funded training, IPs take about the same number of courses as non-immigrant professionals ( $0.32 \mathrm{v}$. 0.34$)$. However, IPs spend more time on the most recently-taken training courses than their non-immigrant counterparts ( 3.0 days v. 2.4 days). In terms of employer-sponsored training, IPs are more likely to work in firms that provide a lower amount of training expenditure (\$397 v. \$418).

In contrast with the non-immigrants, IPs are on average older, more likely to be male, and the majority are of non-European background (71.4 percent v. 16.6 percent). More than 40 percent of them speak an unofficial second language (other than English or French) at home. They are also more likely to be married with dependent children. IPs tend to work in smaller organizations and are less likely work in non-profit organizations. Compared with their native-born counterparts, they are much less likely to be a union member or covered by a collective bargaining agreement ( 20 percent v. 31 percent). They have more years of prior work experience but shorter tenure with their current employer. They are more likely to be on incentive pay and job rotation, but less likely to be a member of a team. In terms of occupational distribution, IPs are more likely to be production workers, and less likely to be managers. 


\begin{tabular}{|c|c|c|c|c|c|c|c|}
\hline \multirow[b]{2}{*}{ Variable } & \multicolumn{2}{|c|}{ All sample } & \multicolumn{2}{|c|}{$\begin{array}{l}\text { Immigrant } \\
\text { sample }\end{array}$} & \multicolumn{2}{|c|}{$\begin{array}{l}\text { Non-immigrant } \\
\text { sample }\end{array}$} & \\
\hline & Mean & SD & Mean & SD & Mean & $\mathrm{SD}$ & \\
\hline Lnwage & 3.252 & 0.505 & 3.189 & 0.492 & 3.278 & 0.508 & \\
\hline Hourly wage & 29.308 & 16.307 & 27.349 & 14.381 & 30.100 & 16.962 & \\
\hline Promotion rate & 0.244 & 0.262 & 0.213 & 0.256 & 0.258 & 0.264 & \\
\hline Job tenure & 7.940 & 7.868 & 7.028 & 7.494 & 8.309 & 7.986 & \\
\hline Job satisfaction & 3.250 & 0.664 & 3.159 & 0.691 & 3.287 & 0.650 & \\
\hline Money satisfaction & 2.973 & 0.732 & 2.883 & 0.758 & 3.009 & 0.718 & \\
\hline Training expenditure per employee & 411.66 & 715.53 & 396.56 & 809.92 & 417.77 & 673.69 & \\
\hline Number of unpaid training courses taken & 0.33 & 1.27 & 0.32 & 0.96 & 0.34 & 1.38 & \\
\hline Days of recent unpaid training courses & 2.57 & 16.21 & 3.03 & 15.67 & 2.38 & 16.42 & \\
\hline Immigrants (before 1970s) & 0.047 & 0.211 & 0.163 & 0.369 & 0 & 0 & \\
\hline Immigrants (1970s) & 0.062 & 0.241 & 0.214 & 0.410 & 0 & 0 & \\
\hline Immigrants (1980s) & 0.063 & 0.243 & 0.218 & 0.413 & 0 & 0 & \\
\hline Recent immigrants & 0.117 & 0.321 & 0.405 & 0.491 & 0 & 0 & \\
\hline Female & 0.525 & 0.499 & 0.472 & 0.499 & 0.547 & 0.498 & \\
\hline European & 0.676 & 0.468 & 0.286 & 0.452 & 0.834 & 0.372 & \\
\hline Non-European & 0.324 & 0.468 & 0.714 & 0.452 & 0.166 & 0.372 & \\
\hline Language at home & 0.130 & 0.336 & 0.403 & 0.491 & 0.019 & 0.137 & \\
\hline Married & 0.580 & 0.494 & 0.671 & 0.470 & 0.544 & 0.498 & \\
\hline Baby $(0-2)$ & 0.102 & 0.302 & 0.125 & 0.330 & 0.093 & 0.290 & \\
\hline Child (3-5) & 0.112 & 0.315 & 0.136 & 0.343 & 0.102 & 0.303 & \\
\hline Female $\times$ married & 0.263 & 0.440 & 0.273 & 0.446 & 0.259 & 0.438 & \\
\hline Female $\times$ baby & 0.032 & 0.176 & 0.036 & 0.187 & 0.030 & 0.171 & \\
\hline Female $\times$ child & 0.052 & 0.221 & 0.066 & 0.248 & 0.046 & 0.209 & \\
\hline Workplace size & 5.048 & 2.146 & 4.698 & 2.066 & 5.189 & 2.161 & \\
\hline Non-profit organization & 0.345 & 0.475 & 0.241 & 0.428 & 0.387 & 0.487 & \\
\hline Foreign ownership & 0.098 & 0.297 & 0.115 & 0.320 & 0.090 & 0.287 & \\
\hline Union member & 0.279 & 0.449 & 0.203 & 0.402 & 0.310 & 0.463 & \\
\hline Training received & 0.657 & 0.475 & 0.636 & 0.481 & 0.666 & 0.472 & \\
\hline Part-time workers & 0.107 & 0.309 & 0.081 & 0.273 & 0.117 & 0.321 & \\
\hline Member of team & 0.704 & 0.457 & 0.675 & 0.468 & 0.716 & 0.451 & \\
\hline Age & 40.589 & 10.394 & 42.434 & 10.594 & 39.842 & 10.220 & \\
\hline Years of experience & 15.777 & 10.157 & 15.949 & 10.536 & 15.707 & 10.001 & \\
\hline Prior work experience & 8.246 & 8.668 & 9.312 & 9.503 & 7.815 & 8.270 & \\
\hline Proportion of part-time workers & 0.246 & 0.263 & 0.216 & 0.260 & 0.258 & 0.264 & \\
\hline Incentive pay & 0.395 & 0.489 & 0.481 & 0.500 & 0.360 & 0.480 & \\
\hline Job rotation & 0.277 & 0.448 & 0.336 & 0.473 & 0.253 & 0.435 & \\
\hline Per capita training expenditure & 411.659 & 715.531 & 396.561 & 809.918 & 417.766 & 673.692 & \\
\hline \multicolumn{8}{|l|}{ Manager } \\
\hline Professional & 0.423 & 0.494 & 0.397 & 0.490 & 0.434 & 0.496 & \\
\hline Technical/trades & 0.197 & 0.398 & 0.203 & 0.403 & 0.195 & 0.396 & \\
\hline Marketing/sales & 0.034 & 0.181 & 0.031 & 0.172 & 0.035 & 0.184 & \\
\hline Clerical workers & 0.071 & 0.257 & 0.078 & 0.268 & 0.068 & 0.252 & Summary statistics for \\
\hline Production workers & 0.014 & 0.116 & 0.031 & 0.173 & 0.007 & 0.082 & main variables of interest \\
\hline$n$ & \multicolumn{2}{|c|}{4,105} & \multicolumn{2}{|c|}{1,004} & \multicolumn{2}{|c|}{3,101} & by immigrant status \\
\hline
\end{tabular}


Based on our findings derived from using the econometric models (see Tables II and III), career self-management behaviors (self-initiated and self-funded) do not appear to affect career success outcomes of either immigrant or non-immigrant professionals. However, there was a positive relationship between employers' investment in training and development (as demonstrated by the training expenditure per employee) and objective career success for non-immigrants. Other employer initiatives such as the presence of job rotation had a positive effect on the subjective career success of both groups. Teamwork had a positive effect on outcomes for non-immigrants, but for immigrants it had a positive outcome only on salary rate and no effect on promotion rate or subjective career success. These results are discussed in more detail below.

\section{Discussion}

As more and more countries are being classified as suppliers or receivers of international labour migrants (Stalker, 2000), the focus on the career path and success of these individuals is an important global concern. This study is focused on individual as well as organizational investments in the human capital of immigrant and non-immigrant professionals in Canada. According to the stock and flow theory of human capital, these investments are expected to increase individuals' career success, as perceived by both subjective and objective career success indicators. This study contributes to the career literature, as it includes both types of career success indicators and examines them for a specific and rarely studied group: immigrant professionals (Thomas and Inkson, 2007).

Testing our first hypothesis, we found that career self-management behaviors (self-initiated and self-funded training) did not affect the career success outcomes of either immigrant or non-immigrant professionals. This finding can be interpreted in several different ways. First, human capital investments are often geared towards finding a new job that has the potential to provide higher pay and more satisfying opportunities than the one currently held. Thus, career success indicators for the current job (job satisfaction, salary, promotion, etc.) may not capture the relationship with future-oriented career self-management investments. In fact, it is also reported that immigrants invest more time in individual training initiatives than do non-immigrants, and this may point towards the desire of IPs to pursue a new area. Obstensibly they may be preparing to engage in a job search that will take them away from their current field. Second, the lack of a relationship with career success indicators at the current job may also indicate that IPs are working hard to compensate for and overcome the "transition penalty" (Lochhead, 2003) by acquiring domestic career capital that is needed for a career or job change that will eventually increase their employability (Inkson and Arthur, 2001). Third, given that IPs on average work for employers that offer less training, as mentioned above, they also may be trying to compensate for that by pursuing their own training and development independent of the employer.

Our second hypothesis examined the relationship between employers' investment in their employees' human capital and career success. We found a positive relationship between employers' investment in training and development (as indicated by training expenditure per employee), and objective career success indicators (wage and promotions) for non-immigrants but not for IPs. Hence, controlling for everything else, the return for every additional training dollar is higher for non-immigrants than for 


\begin{tabular}{|c|c|c|c|c|c|c|c|c|}
\hline & lnwage & $t$ & prom_rate & $t$ & satjob & $t$ & satmon & $t$ \\
\hline Years of education & $0.034^{* * *}$ & 3.33 & $0.052^{*}$ & 1.73 & 0.018 & 0.97 & 0.018 & 0.85 \\
\hline Female & $-0.056^{*}$ & -1.72 & -0.102 & -0.95 & $-0.155^{* *}$ & -2.75 & -0.108 & -1.52 \\
\hline Married & $0.059^{*}$ & 1.81 & -0.133 & -1.16 & -0.041 & -0.67 & 0.020 & 0.29 \\
\hline Female $\times$ married & -0.019 & -0.47 & 0.191 & 1.27 & $0.193^{* *}$ & 2.48 & $0.207^{* *}$ & 2.3 \\
\hline Baby $(0-2)$ & $0.088^{* *}$ & 2.17 & 0.017 & 0.13 & -0.007 & -0.09 & -0.085 & -0.79 \\
\hline Female $\times$ baby & -0.093 & -1.64 & 0.099 & 0.58 & -0.128 & -0.97 & -0.019 & -0.14 \\
\hline Child (3-5) & $0.098^{* *}$ & 2.12 & 0.130 & 1.17 & -0.026 & -0.36 & 0.023 & 0.31 \\
\hline Female $\times$ child & -0.006 & -0.1 & 0.000 & 0 & 0.012 & 0.1 & 0.127 & 113 \\
\hline Non-European & 0.013 & 0.5 & 0.086 & 0.94 & -0.074 & -1.41 & -0.031 & -0.44 \\
\hline Language at home & 0.010 & 0.12 & -0.207 & -0.49 & 0.193 & 1.05 & -0.042 & -0.19 \\
\hline $\begin{array}{l}\text { Manager } \\
\text { Professional }\end{array}$ & $-0169^{* * *}$ & -578 & $-0.225^{* *}$ & -268 & $-0102^{*}$ & -187 & $-0171 * * *$ & -271 \\
\hline $\begin{array}{l}\text { Trotessional } \\
\text { Technical/trades }\end{array}$ & $\begin{array}{l}-0.169 \\
-0.377^{* * *}\end{array}$ & $\begin{array}{r}-5.8 \\
-10.64\end{array}$ & $\begin{array}{l}-0.225 \\
-0.076\end{array}$ & $\begin{array}{l}-2.68 \\
-0.83\end{array}$ & $\begin{array}{l}-0.102 * * * \\
-0.230\end{array}$ & $\begin{array}{l}-1.81 \\
-3.76\end{array}$ & $\begin{array}{l}-0.171 \\
-0.182^{* *}\end{array}$ & $\begin{array}{l}-2.71 \\
-2.49\end{array}$ \\
\hline Marketing/sales & $-0.474^{* * *}$ & -5.02 & -0.436 & -1.06 & $-0.460^{* * *}$ & -3.47 & -0.006 & -0.04 \\
\hline Clerical workers & $-0.667 * * *$ & -16.79 & 0.041 & 0.28 & $-0.171^{* *}$ & -2.11 & -0.163 & -1.43 \\
\hline Production workers & $-0.675 * * *$ & -7.35 & -0.282 & -0.7 & -0.008 & -0.05 & $0.363^{* *}$ & 2.04 \\
\hline Prior work experience & $0.011^{* * *}$ & 7.27 & $-0.013^{* *}$ & -2.69 & -0.003 & -1.16 & 0.001 & 0.44 \\
\hline Tenure & $0.015^{* * *}$ & 9.69 & $0.047^{* * *}$ & 10.76 & 0.002 & 1.05 & 0.002 & 0.57 \\
\hline Workplace size & $0.043^{* * *}$ & 6.44 & 0.001 & 0.05 & $-0.027 * *$ & -2.53 & 0.015 & 1.03 \\
\hline Part-time worker & -0.068 & -1.58 & $-0.375 * * *$ & -2.75 & $0.181^{* * *}$ & 3.03 & 0.091 & 1.07 \\
\hline Union member & $0.043^{*}$ & 1.74 & 0.063 & 0.73 & 0.012 & 0.23 & 0.025 & 0.4 \\
\hline Non-profit organization & $-0.094^{* *}$ & -2.08 & $-0.185^{*}$ & -1.76 & 0.122 & 1.6 & $-0.128^{*}$ & -1.71 \\
\hline Foreign ownership & -0.027 & -0.72 & -0.068 & -0.58 & -0.035 & -0.61 & 0.025 & 0.35 \\
\hline Member of a team & $0.046^{*}$ & 1.74 & $0.176^{* *}$ & 2.28 & $0.123 * *$ & 2.55 & 0.077 & 1.37 \\
\hline Job rotation & $-0.075 * *$ & -2.99 & 0.027 & 0.33 & $0.088^{* *}$ & 2.1 & -0.011 & -0.22 \\
\hline Incentive pay & $0.139^{* * *}$ & 5.33 & 0.126 & 1.63 & $0.096^{* *}$ & 2.13 & $0.127 * *$ & 2.06 \\
\hline Number of unpaid courses & -0.005 & -0.63 & 0.003 & 0.12 & 0.000 & 0 & 0.016 & 1.09 \\
\hline Per capita training expenditure & $0.000 * *$ & 1.97 & $0.000^{* *}$ & 2.63 & 0.000 & 0.66 & 0.000 & 0.24 \\
\hline Proportion of part-time workers & $-0.264^{* * *}$ & -3.96 & 0.282 & 1.45 & 0.065 & 0.61 & $0.262 * *$ & 2.00 \\
\hline Constant & $2.495 * * *$ & 12.97 & $-1.225 * *$ & -2.29 & $3.318^{* * *}$ & 9.96 & $2.571 * * *$ & 6.75 \\
\hline$n$ & \multicolumn{2}{|c|}{3,101} & \multicolumn{2}{|c|}{3,007} & \multicolumn{2}{|c|}{3,096} & \multicolumn{2}{|c|}{3,097} \\
\hline
\end{tabular}

Notes: Models have included regions (5 categories), industries (13 categories) and all other explanatory variables shown in Table $I_{*}$ absolute values of $t$ statistics based on robust standard errors are shown in the column to the right of column of the coefficients; ${ }^{*}$ significant at $10 \% ;^{* *}$ significant at $5 \%$; significant at $1 \%$ 


\begin{tabular}{|c|c|c|c|c|c|c|c|c|}
\hline & lnwage & $t$ & Prom_rate & $t$ & satjob & $t$ & satmon & $t$ \\
\hline $\begin{array}{l}\text { Years of education } \\
\text { Immigrants: before 1970s }\end{array}$ & $0.068^{* * *}$ & 3.98 & $-0.112^{* *}$ & -2.43 & 0.016 & 0.55 & 0.019 & 0.49 \\
\hline $\begin{array}{l}\text { mmigrants: before } 1970 \mathrm{~s} \\
\text { Immigrants: } 1970 \mathrm{~s}\end{array}$ & $0.129^{* *}$ & 2.38 & $0.283^{* *}$ & 2.24 & 0.078 & 070 & 0.218 & 1.40 \\
\hline Immigrants: $1980 \mathrm{~s}$ & -0.018 & -0.23 & 0.203 & 1.26 & -0.224 & -1.63 & 0.269 & 1.63 \\
\hline Recent immigrants & $-0.161^{* *}$ & -2.25 & 0.207 & 1.26 & -0.074 & -0.56 & 0.168 & 1.58 \\
\hline Female & 0.053 & 0.89 & 0.189 & 1.12 & -0.198 & -1.65 & -0.035 & -0.24 \\
\hline Married & $0.191^{* * *}$ & 2.99 & 0.073 & 0.49 & -0.139 & -1.21 & -0.001 & -0.01 \\
\hline Female $\times$ married & $-0.242^{* * *}$ & -2.93 & -0.269 & -1.15 & $0.357^{* *}$ & 2.28 & 0.135 & 0.71 \\
\hline Baby $(0-2)$ & 0.075 & 1.28 & -0.215 & -0.98 & 0.120 & 0.83 & 0.004 & 0.03 \\
\hline Female $\times$ baby & -0.038 & -0.39 & 0.403 & 1.21 & -0.079 & -0.38 & -0.502 & -1.60 \\
\hline Child (3-5) & 0.038 & 0.70 & 0.076 & 0.41 & 0.169 & 1.24 & 0.057 & 0.41 \\
\hline Female $\times$ child & 0.004 & 0.05 & 0.032 & 0.11 & 0.013 & 0.06 & -0.008 & -0.03 \\
\hline Non-European & -0.035 & -0.99 & -0.060 & -0.51 & -0.117 & -1.43 & -0.059 & -0.65 \\
\hline Language at home & -0.069 & -1.44 & -0.036 & -0.30 & -0.014 & -0.16 & 0.021 & 0.24 \\
\hline $\begin{array}{l}\text { Manager } \\
\text { Professional }\end{array}$ & 0.0 & 0.43 & -0.027 & -0.19 & $-0176^{*}$ & & $-0230 * *$ & -2.11 \\
\hline Technical/trades & $-0.316 * * *$ & -3.96 & 0.076 & 0.50 & $-0.222 *$ & $\begin{array}{l}-1.73 \\
-1.91\end{array}$ & $\begin{array}{l}-0.230 \\
-0.320\end{array}$ & $\begin{array}{l}-2.11 \\
-1.84\end{array}$ \\
\hline Marketing/sales & $-0.485^{* * *}$ & -3.97 & 0.322 & 1.17 & $-0.666 * * *$ & -3.32 & $-0.532 * * *$ & -2.87 \\
\hline Clerical workers & $-0.320^{* * *}$ & -4.25 & 0.067 & 0.37 & $-0.240^{*}$ & -1.80 & $-0.354^{* *}$ & -2.51 \\
\hline Production workers & $-0.605^{* * *}$ & -5.99 & -0.842 & -1.93 & -0.022 & -0.08 & -0.303 & -0.97 \\
\hline Prior work experience & 0.003 & 1.61 & $-0.001 *$ & -0.28 & $0.017^{* * *}$ & 4.35 & 0.003 & 0.88 \\
\hline Tenure & $0.009^{* * *}$ & 2.88 & $0.061^{* * *}$ & 7.94 & $0.011^{*}$ & 1.89 & $0.012^{* *}$ & 2.16 \\
\hline Workplace size & $0.030^{* * *}$ & 3.30 & 0.036 & 1.13 & -0.003 & -0.15 & -0.010 & -0.45 \\
\hline Part-time worker & 0.023 & 0.43 & -0.150 & -1.00 & 0.166 & 1.40 & 0.030 & 0.20 \\
\hline Union member & $0.072^{*}$ & 1.90 & -0.053 & -0.43 & 0.068 & 0.79 & $0.250^{* *}$ & 2.39 \\
\hline Non-profit organization & 0.039 & 0.63 & -0.185 & -1.30 & $0.183^{*}$ & 1.83 & $0.279^{* *}$ & 2.29 \\
\hline $\begin{array}{l}\text { Foreign ownership } \\
\text { - }\end{array}$ & 0.022 & 0.42 & 0.028 & 0.17 & -0.092 & -0.93 & 0.038 & 0.36 \\
\hline Member of a team & $0.072^{*}$ & 1.84 & 0.039 & 0.40 & 0.015 & 0.18 & -0.137 & -1.51 \\
\hline Job rotation & $-0.071^{* *}$ & -2.22 & 0.042 * & 0.37 & $0.151^{* *}$ & 2.44 & $0.105 *$ & 1.39 \\
\hline Incentive pay & $0.118^{* * *}$ & 3.13 & $0.268^{* *}$ & 2.24 & -0.001 & -0.01 & $0.151^{*}$ & 1.84 \\
\hline Number of unpaid courses & -0.003 & -0.23 & -0.089 & -1.39 & -0.027 & -0.74 & $-0.079^{* *}$ & -2.06 \\
\hline Per capita training expenditure & 0.000 & 0.71 & 0.000 & -1.04 & 0.000 & -0.66 & 0.000 & -0.02 \\
\hline Proportion of part-time workers & $-0.287^{* * *}$ & -3.58 & 0.304 & 1.49 & -0.094 & -0.56 & -0.042 & -0.24 \\
\hline Constant & $1.321^{* * *}$ & 3.96 & -0.292 & -0.36 & $3.348^{*}$ & 5.88 & $2.845^{* * *}$ & 4.10 \\
\hline$n$ & 1,0 & & 97 & & 1,0 & & 1,0 & \\
\hline
\end{tabular}

$n$

1,003

Notes: Models have included regions ( 5 categories), industries (13 categories) and all other explanatory variables shown in Table I; absolute values of $t$-statistics based on robust standard errors are shown in the column to the right of column of the coefficients; ${ }^{*}$ significant at $10 \%$; ${ }^{*}{ }^{*}$ significant at $5 \%$; significant at $1 \%$ 
comparable immigrants. It is interesting to note also that, on average, both groups were equally likely to undergo training and development initiatives funded by the employer. Thus, non-immigrants may be better able to leverage their training and, as a result, achieve higher salaries and more promotions. This advantage on the part of non-immigrant earnings has also been noted in previous research (Fang and Heywood, 2006).

The IPs' lack of familiarity with local training methods and/or their lack of official language skills may, however, result in barriers preventing them from more effectively "translating" training results into practice. Therefore, we suggest that training and development practices be accompanied by additional cross-cultural training for the IPs in order to provide sensitivity with regard to culture-specific training and development methods and communication (Novicevic et al., 2003). In this way, the investments made in the flow of human capital by the organization may be capitalized in a more balanced way by both groups of employees: immigrant professionals and non-immigrant professionals. Another alternative interpretation of this finding is that the presence of certain biases and stereotypes may prevent IPs from gaining salary increases and promotions, irrespective of their training or skill level. Although this last hypothesis may be more challenging to test, it can be addressed by future research.

Some other potential investments by the employer, such as being immersed in a team culture and working as part of a team, had a positive relationship with the career success indicators of non-immigrants. In fact, all three success indicators (salary, promotion, and job satisfaction) were positively related to team membership for non-immigrants. In the case of IPs, though, the only positive relationship was with the objective indicator (salary). Moreover, there was no relationship between team membership and promotions or job satisfaction for IPs. Again it seems that local workers have some sort of advantage in terms of teamwork. Possibly non-immigrants may "fit" better in the team culture because it is more familiar to them as part of their past educational and work experiences. Immigrants may not thrive as well in teams, potentially because, depending on their background, teamwork may be somewhat new to them.

Finally, another indicator of employers' investment is the opportunity for employees to take part in job rotation and, in this way, learn more about different types of jobs within the same organization. This strategy will most likely increase employability by adding new experiences to existing human capital stock. Our results show that both employee groups benefit in similar ways. Job rotation had a positive relationship with job satisfaction for both groups. Thus, trying different types of jobs may not increase one's objective career success, but the potential variety increases one's enjoyment of the job as indicated by job satisfaction.

\section{Implications for HRM, limitations, and future research directions}

Our findings raise some interesting questions not only about the ability of non-immigrants to leverage organizational investments but also about the paths of human capital flows in organizations. On the one hand, being a member of a team and receiving organizational investments in terms of training expenditure appear to increase both promotion rate and salary for non-immigrants. However, this is not the case for IPs, suggesting that non-immigrants tend to be rewarded more often for their learning, interpersonal skills, and team engagement than do IPs. On the other hand, as 
immigrants on incentive pay are more likely to be promoted, it appears that IPs benefit more from reward programs that are based on objective performance outcomes rather than on those based on interpersonal skills such as teamwork which is generally evaluated more subjectively. A related question that needs further investigation is whether our findings relate to general local attitude and culture and/or HR practices that in some way favor local workers.

Another related but broader issue, which is probably more difficult to address, is the influence of national culture on human resource management (HRM) policies and practices. As reported recently, national culture influences organizational culture and values, and in turn, it shapes the way HRM is practiced (Stone et al., 2007). Therefore, there may be a host of negative consequences for immigrants whose culture differs from that of the dominant culture and established ways of doing business in their new country of residence. As a result, future research should focus on the multi-level study of immigrant careers. Specifically, researchers should expand their agenda to include macro level influences and to determine how, together with organizational and individual-level variables (Syed, 2008), these macro influences may impact on immigrant career success.

In terms of other implications for HRM, this study suggests that, in order to achieve the successful integration of IPs, organizations should revisit their training and development programs and assess the impact of those programs on the flow of human capital. In particular, the assessment should address the benefits of these initiatives for a diverse employee workforce, as these are some of the topics that are currently prominent on various international training agendas (Herfst et al., 2008; Schmidt, 2004). Moreover, if IPs are investing more time in additional self-initiated and self-sponsored training, it is suggested that an examination of whether they are leaving for better jobs as a result of low satisfaction and objective career outcomes in their current jobs would be worthwhile.

Evidently, employers need to revisit strategies regarding who receives training and how this type of human capital flow may be circulated among domestic versus foreign workers. These two groups may need very different types of training. For example, recent research points to the importance of cultural intelligence and training in this area, especially in the Canadian context where working in a multicultural environment is a norm for all (Ang et al., 2007). It is also suggested that these metrics should possibly be embedded as part of the performance evaluation system for all employees (Ang et al., 2007).

Overall, the results of this Canadian based study indicate that there is definitely a need for employers to develop better policies for integrating and leveraging the talent that IPs bring with them, thus increasing the probability of their career success in the host country. In particular, an organizational culture of "inclusiveness" evident at all levels of the organization is likely to be conducive to the effective integration of IPs. The economic value of inclusive culture is evidenced by the fact that minority-friendly companies consistently outperform Fortune 500 index companies in terms of financial performance (Warner, 2000). In Canada, for example, according to TRIEC (2008) (www.hireimmigrants.ca a program/website established by the Toronto Region Immigrant Employment Council (TRIEC) to assist employers in recruiting, retaining, and promoting skilled immigrants), the Canadian economy missed out on about $\$ 4.0-5.9$ billion by not recognizing the credentials and experience of skilled immigrants. 
If these newcomers were able to find solid employment, an estimated $\$ 3.4$ billion could be added to the economy.

In terms of the limitations of this study, it is worth noting that due to the somewhat small sample of IPs it is not further broken down into sub-samples. Therefore, we were prevented from analyzing the data further based on ethnic background (Asians, Blacks, Aboriginals, etc.). In addition, the WES is a longitudinal survey that follows employees for two consecutive years. It would be informative to conduct panel data analysis to examine the causal effect of various HR practices on the career progression of immigrant and non-immigrant professionals. However, the sample design of the WES drops individual employees out of the sample when they quit or are laid off.

Finally, some of the human capital investments by either party (employees or employers) may actually pay off in the long run differentially, although in this particular study we are not able to follow these same individuals to the next job. Thus, longitudinal data would help us to understand the long-term impact of capital investments. In addition, it would also be important to know the specific type of training undergone by these individuals - that is, technical, interpersonal, or any other type - and to determine the relevance of a specific type of training for the particular job performance indicator. Our training measure is a global one as it is based on expenditure, but we cannot determine the exact training focus. This limitation may be addressed in future studies. Similarly, this data set lacks the richness of qualitative data, thus it would be valuable to combine this type of data with interviews that would allow for further understanding of the motivations behind immigrant human capital stock and flow.

\section{Conclusion}

This study is original and makes a unique contribution because it combines the individualistic and organizational perspectives on the stock and flow of human capital of immigrant professionals. While most previous research has focused on the individualistic approach and on capital investments made by the immigrant, this study addresses the equally important organizational perspective. This focus on the organizational perspective concerns what can be done through the systems and structures in which immigrants are immersed in order to address the career success issues of the increasingly international labour force. Our findings provide a new perspective on the management and integration of IPs and have specific implications for human resource professionals.

In conclusion, while the study is not without limitations, it presents a broader perspective on immigrant careers by examining specific career outcomes, career self-management activities, and organizational investments in immigrant versus non-immigrant professionals. The study aims to increase our knowledge regarding the role of human capital investments and their effect on the career success of different groups (Heslin, 2005). We believe that this evidence will enhance our understanding of the determining factors for immigrant career pathways and various career outcomes, as well as provide some practical implications for training and development programs and human resource management in general to meet the specific needs of immigrant professionals. 


\section{Notes}

1. This is unavailable in most data sets, in which years of experience must be estimated using the formula: Experience $=$ Years of age - Years of schooling - 5 .

2. All estimations are done in Stata 9 using the "survey" commands and identifying the underlying establishments as the primary survey units. This automatically generates robust standard errors while the use of the survey weights returns consistent point estimates.

\section{References}

Alboim, N. and McIsaac, E. (2007), "Making the connections: Ottawa's role in immigrant employment", Immigration and Refugee Policy, Vol. 13 No. 3, pp. 1-24.

Alboim, N., Finnie, R. and Meng, R. (2005), "The discounting of immigrants' skills in Canada", Evidence and Policy, IRPP Choices, Vol. 11 No. 1.

Ang, S., Van Dyne, L., Koh, C., Ng, K.Y., Templar, K.J., Tay, C. and Chandrasekar, N.A. (2007), "Cultural intelligence: its measurement and effects on cultural judgment and decision making, cultural adaptation and task performance", Management and Organization Review, Vol. 3 No. 3, pp. 335-71.

Arthur, M.B., Hall, D.T. and Lawrence, B.S. (Eds) (1989), Handbook of Career Theory, Cambridge University Press, New York, NY, pp. 329-53.

Arthur, M.B., Khapova, S.M. and Wilderom, C.P.M. (2005), "Career success in a boundaryless career world", Journal of Organizational Behavior, Vol. 26, pp. 177-202.

Barley, S.R. (1989), "Careers, identities and institutions: the legacy of the Chicago School of Sociology", in Arthur, M.B., Hall, D.T. and Lawrence, B.S. (Eds), Handbook of Career Theory, Cambridge University Press, New York, NY, pp. 41-65.

Becker, G.S. (1964), Human Capital: A Theoretical and Empirical Analysis, with Special Reference to Education, University of Chicago Press, Chicago, IL.

Bhagat, R.S. and London, M. (1999), "Getting started and getting ahead: career dynamics of immigrants", Human Resource Management Review, Vol. 9 No. 3, pp. 349-65.

Carr, S.C., Inkson, K. and Thorn, K. (2005), "Talent flow and global careers: reinterpreting brain drain", Journal of World Business, Vol. 40, pp. 386-98.

Chapman, D.S., Uggerslev, K.L., Carroll, S.A., Piasentin, K.A. and Jones, D.A. (2005), "Applicant attraction to organizations and job choice: a meta-analytic review of the correlates of recruiting outcomes", Journal of Applied Psychology, Vol. 90, pp. 928-44.

Chiswick, B.R. (1978), "The effect of Americanization on the earnings of foreign-born men", The Journal of Political Economy, Vol. 86 No. 5, pp. 897-921.

Chiswick, B.R., Lee, Y.L. and Miller, P.W. (2005), "A longitudinal analysis of immigrant occupational mobility: a test of the immigrant assimilation hypothesis", The International Migration Review, Vol. 39 No. 2, pp. 332-53.

Cobb-Clark, D.A., Connolly, M.D. and Worswick, C. (2005), "Post-migration investments in education and job search: a family perspective”, Journal of Population Economics, Vol. 18, pp. 663-90.

Fang, T. and Heywood, J.S. (2006), "Output pay and ethnic wage differentials: Canadian evidence", Industrial Relations, Vol. 45 No. 2, pp. 173-94.

Favell, A., Feldblum, M. and Smith, M.P. (2006), "The human face of global mobility: a research agenda", in Smith, M.P. and Favell, A. (Eds), The Human Face of Global Mobility: International Highly Skilled Migration in Europe, North America and the Asia-Pacific, Comparative Urban and Community Research, Vol. 8, Transaction Press, New Brunswick, NJ. 
Friedberg, R.M. (2000), "You can't take it with you? Immigrant assimilation and the portability of human capital", Journal of Labor Economics, Vol. 18 No. 2, pp. 221-51.

Gunz, H. (1989), "The dual meaning of managerial careers: organisational and individual levels of analysis", Journal of Management Studies, Vol. 26 No. 3, pp. 225-50.

Herfst, S., van Oudenhoven, J.P. and Timmerman, M.E. (2008), "Intercultural effectiveness training in three western immigrant countries: a cross-cultural evaluation of critical incidents", International Journal of Intercultural Relations, Vol. 32 No. 1, pp. 67-80.

Heslin, P.A. (2005), “Conceptualizing and evaluating career success”, Journal of Organizational Behavior, Vol. 26 No. 2, pp. 113-36.

Inkson, K. and Arthur, M.B. (2001), "How to be a career capitalist", Organizational Dynamics, Vol. 30 No. 1, pp. 48-61.

Iredale, R. (2001), "The migration of professionals: theories and typologies", International Migration, Vol. 39 No. 5, pp. 7-26.

Judge, T.A. and Bretz, R.D. (1994), "Political influence behavior and career success", Journal of Management, Vol. 20 No. 1, pp. 43-65.

Judge, T.A., Cable, D.M., Boudreau, J.W. and Bretz, R.D. Jr (1995), "An empirical investigation of the predictors of executive career success", Personnel Psychology, Vol. 48, pp. 485-517.

Kogan, I. (2006), "Labor markets and economic incorporation among recent immigrants in Europe", Social Forces, Vol. 85 No. 2, pp. 697-721.

Kossek, E.E., Roberts, K., Fisher, S. and Demarr, B. (1998), "Career self-management: a quasi-experimental assessment of the effects of a training intervention", Personnel Psychology, Vol. 51 No. 4, pp. 935-62.

Lochhead, C. (2003), The Transition Penalty: Unemployment among Recent Immigrants to Canada, Canadian Labour and Business Centre, Ottawa.

Mirvis, P.H. and Hall, D.T. (1996), "Psychological success and the boundaryless career", Journal of Vocational Behaviour, Vol. 15, pp. 365-80.

Ng, E.S.W. and Burke, R.J. (2005), "Person-organization fit and the war for talent: does diversity management make a difference?", International Journal of Human Resource Management, Vol. 16 No. 7, pp. 1195-210.

Novicevic, M.N., Buckley, R.M., Harvey, M., Halbesleben, J.R.B. and Des Rosiers, S. (2003), "Socializing ethical behavior of foreign employees in multinational corporations", Business Ethics: A European Review, Vol. 12 No. 3, pp. 298-307.

Peixoto, J. (2001), "The international mobility of highly skilled workers in transnational corporations: the macro and micro factors of the organization migration of cadres", International Migration Review, Vol. 35 No. 4, pp. 1030-53.

Reitz, J.G. (2001), "Immigrant success in the knowledge economy: institutional change and the immigrant experience in Canada 1970-1995", Journal of Social Issues, Vol. 57 No. 3, pp. 579-613.

Reitz, J.G. (2007a), "Immigrant employment success in Canada, Part I: Individual and contextual causes", Journal of International Migration and Integration, Vol. 8 No. 1, pp. 11-36.

Reitz, J.G. (2007b), "Immigrant employment success in Canada, Part II: Understanding the decline", Journal of International Migration and Integration, Vol. 8 No. 1, pp. 37-62.

Salaff, J.W., Greve, A. and Xu Li Ping, L. (2002), "Paths into the economy: structural barriers and the job hunt for skilled PRC migrants in Canada", International Journal of Human Resource Management, Vol. 13 No. 3, pp. 450-64.

Schmidt, P. (2004), "An approach to diversity training in Canada", Industrial and Commercial Training, Vol. 36 No. 4, pp. 148-52. 
Seibert, S.E., Crant, M.J. and Kraimer, M.L. (1999), "Proactive personality and career success", Journal of Applied Psychology, Vol. 84 No. 3, pp. 416-27.

Stalker, P. (2000), Workers without Frontiers: The Impact of Globalization on International Migration, International Labour Organization, Geneva.

Statistics Canada (2007), Guide to the Analysis of the Workplace and Employee Survey, Vol. 2004, Statistics Canada, Ottawa.

Stebbins, R.A. (1970), "Career: the subjective approach", Sociological Quarterly, Vol. 11, pp. 32-49.

Stock, J.H. and Watson, M.W. (2003), Introduction to Econometrics, Pearson Educational Publishing, Boston, MA.

Stone, D., Stone-Romero, E. and Lukaszewski, K. (2007), "The impact of cultural values on the acceptance and effectiveness of human resource management policies and practices", Human Resource Management Review, Vol. 17, pp. 152-65.

Syed, J. (2008), "Employment prospects for skilled immigrants: a relational perspective", Human Resource Management Review, Vol. 18 No. 1, pp. 28-45.

Thomas, D.C. and Inkson, K. (2007), "Careers across cultures", in Thomas, D.C. and Inkson, K. (Eds), Handbook of Career Studies, Sage Publications, London.

Toronto Region Immigrant Employment Council (TRIEC) (2007), Toronto Region Immigrant Employment Council, available at: www.hireimmigrants.ca/why/why2.php (accessed September 3, 2007).

Warner, M. (2000), "The Indians of Silicon Valley", Fortune, Vol. 141 No. 10, pp. 356-7.

Zikic, J. and Klehe, U. (2006), "Job loss as a blessing in disguise: the role of career exploration and career planning in predicting reemployment quality", Journal of Vocational Behavior, Vol. 69 No. 3, pp. 391-401.

Zikic, J., Novicevic, M.N., Harvey, M. and Breland, J. (2006), "Repatriate career exploration: a path to career growth and success", Career Development International, Vol. 11 No. 7, pp. 633-49.

\section{About the authors}

Tony Fang ( $\mathrm{PhD}$, University of Toronto) is an Assistant Professor of Human Resources Management at York University and a research associate at University of Toronto. He has published widely in the areas of compensation and benefits, high performance workplace practices, pension, retirement policy and the ageing workforce, education, immigration, and minimum wages, union impact on wages, innovation and firm growth, pay equity and employment equity. Tony Fang is the corresponding author and can be contacted at: tonyfang@yorku.ca

Jelena Zikic (PhD, University of Toronto) is an Assistant Professor at York University. She has developed part of her career internationally and is currently involved in several cross-cultural projects. She developed her research program and expertise in career transitions of diverse populations, stress and coping and career development theory. Dr Zikic has presented at national and international conferences and her work appeared in various refereed journals. She is the recipient of the Verity International prize for the best paper in management in 2007 and the Literati Award from Emerald Publishing for her Highly Commended Paper.

Milorad M. Novicevic ( $\mathrm{PhD}$ University of Oklahoma) is an Associate Professor of Management at the University of Mississippi. His research focuses on strategic global HRM. He has published more than 100 articles in various refereed journals. 